\title{
Tres temas sobre arbitraje y Administración Pública
}

Juan Pablo Aguilar Andrade ${ }^{1}$

\section{Sumario}

1. Una revisión histórica 2. Arbitraje en derecho 3. La publicidad del arbitraje 4. La autorización del Procurador General del Estado

\section{UNA REVISIÓN HISTÓRICA}

En el Derecho Administrativo ecuatoriano, el arbitraje no surge como una respuesta de los administrativistas a problemas propios de su área de trabajo; se trata más bien de una institución que se impone desde fuera, se desarrolla en el mundo del Derecho Privado e invade los espacios de la administración pública, donde siempre se le ha percibido como un cuerpo extraño.

De aquí se derivan algunos problemas que son el resultado, por una parte, del recelo de la administración pública, y por otra, aunque parezca contradictorio, de la aceptación sin beneficio de inventario de una construcción privatista, que no toma en cuenta las particularidades del Derecho Administrativo. El arbitraje se acepta porque no queda más remedio, pero se busca la manera de hacerlo a un lado y, sobre todo, no existe la más mínima preocupación por entender cómo debería funcionar cuando una de las partes es una institución del sector público.

1. Doctor en Jurisprudencia por la Pontificia Universidad Católica del Ecuador. Profesor de Derecho Administrativo en la Universidad San Francisco de Quito. 
En las páginas siguientes me referiré a tres de esos problemas: el arbitraje en derecho, la publicidad del arbitraje y la autorización previa de la Procuraduría General del Estado, y los analizaré desde el punto de vista del Derecho Administrativo. Para ello, sin embargo, considero indispensable empezar con un análisis histórico de la forma en que el ordenamiento jurídico ecuatoriano ha aplicado la institución arbitral a la administración pública.

La posibilidad de que las instituciones del sector público recurran al arbitraje para solucionar controversias de carácter contractual se admite plenamente, en el Ecuador, a partir de la promulgación de la Ley de Arbitraje y Mediación, el 4 de septiembre de $1997^{2}$.

Con anterioridad regía la Ley de Arbitraje Comercial ${ }^{3}$. Las normas de ésta, sin embargo, por expreso mandato de sus artículos 1 y 5 , se referían exclusivamente a controversias de carácter mercantil, por lo que nunca se la consideró aplicable a las entidades del sector público.

El artículo 956 y los siguientes del Código de Procedimiento Civil $^{4}$ preveían la posibilidad de que las personas jurídicas de derecho público se sometieran a arbitraje. Sin embargo, como se desprende del artículo 958, esto solo ocurría en el caso de controversias que ya se hubieran presentado (por eso se exigía que el compromiso de arbitraje incluyera el texto completo de la demanda y aquello en que consista ésta); no era posible, entonces, incluir en un contrato una cláusula que estableciera el arbitraje como solución posible para eventuales controversias.

A las dificultades y limitaciones que se han indicado se sumaba la existencia de un criterio generalmente aceptado en la práctica administrativa, que negaba la posibilidad de que la administración se someta a procedimientos arbitrales. El funda-

2. Registro Oficial 145 de 4 de septiembre de 1997, artículo 4.

3. Registro Oficial 90 de 28 de octubre de 1963.

4. Suplemento del Registro Oficial 687 de 18 de mayo de 1987. 
mento para ello era el entonces vigente artículo 1505 del Código Civil, el cual brindaba un ejemplo de lo que constituye objeto ilícito por contravenir al Derecho Público Ecuatoriano: "la promesa de someterse en el Ecuador a una jurisdicción no reconocida por las leyes ecuatorianas", que por lo tanto debe considerarse como "nula por vicio del objeto".

La interpretación que la jurisprudencia ecuatoriana dio a esta norma fue muy estricta, incluso cuando se trataba de convenios entre particulares ${ }^{5}$; tratándose de la administración, se asumía que para las controversias contractuales existía una jurisdicción claramente establecida por el artículo 17 de la entonces vigente Ley Orgánica del Ministerio Público ${ }^{6}$, según el cual las controversias contractuales debían ser conocidas en primera y segunda instancia por la Corte Suprema de Justicia cuando las instituciones del Estado fueren demandadas. Para el caso de que se demandara al contratista, la reforma a la Ley de Licitaciones y Concurso de Ofertas, contenida en el artículo 13 del Decreto Ley 157, disponía que los jueces competentes debían ser los de lo civil en primera instancia, y las cortes superiores en segunda.

Siendo así, no era dable que las instituciones del Estado eludieran el cumplimiento del mandato de las normas citadas y establecieran la posibilidad de acudir ante una jurisdicción distinta; si lo hacían, caían en el supuesto de objeto ilícito previsto por el ya citado artículo 1505 del Código Civil.

Esta forma de entender las cosas respondía, por otra parte, a un enfoque tradicional que, al considerar que la administración está sometida, en última instancia, a la legalidad, incluso cuando ejerce potestades discrecionales, queda fuera del ámbito de lo transable. Juan Manuel Trayter expone muy bien este punto de vista, para el caso español, en el siguiente texto:

5. Pueden verse las sentencias de 10 de junio de 1968 (Gaceta Judicial, serie XI, número 8, p. 1064) y de 13 de septiembre de 1976 (Gaceta Judicial, serie XII, número 13, p. 2905).

6. Registro Oficial 871 de 10 de julio de 1979.

7. Registro Oficial 258 de 27 de agosto de 1985. 
El Derecho pública ha contemplado con muchas cautelas la posibilidad de resolver los conflictos en que interviene una Administración Públion mediante arbitraje. La razón, cono hemos ya explicado, hunde sus ruices en la necesidad que las cuestiones litigiosas surgidas $o$ que pueden surgir, para que sean susceptibles de arbitraje, dehen ser materias de hibre disposición de las partes.... Este requisito no se cumple, desde la óptica juridico-pública, cuando la Adminisfración ejerce potestades regladas ( pues la ley determina todos y cada tuno de los comportamientos de la Administración), siendo más discutible esa afirmación referida a las potestades discrecionales, pues ahf, en principio, caben diversas opciones, todas ellas justas. Sin embargo, la globatidad de la actuación administratioa está vinculada al pristipio de legalidad ...., unculación que en una interpretación extensa se opondría al concepto de libre disposición. ${ }^{8}$

Habia un argumento de fondo para negar que la administración pueda someter sus controversias a arbitraje: el poder público, el ejercicio de las potestades administrativas, no podian ser juzgados fuera del ámbito de la Función Judicial. Eso habría sido tanto como violentar el orden público y dejar librado este último a la voluntad de los privados.

Esta forma de entender las cosas solo fue modificada con la promulgación, en 1997, de la ya citada Ley de Arbitraje y Mediación, que admite expresamente la posibilidad de que la administración someta a arbitraje sus controversias contractuales. Es bueno hacer notar que entre las reformas que introdujo la Ley de Arbitraje y Mediación se encontraba la derogatoria, en el artículo 1505 del Código Civil, de la parte final, el ejemplo según el cual la promesa de someterse en el Ecuador a una jurisdicción no reconocida por las leyes ecuatorianas, era nula por vicio del objeto".

Como muestra de lo dicho, puede verse el oficio 7513 , de 16 de septiembre de 1999, en el que la Procuraduria General del Estado sostiene que es recién a partir de la publicación de la indicada Ley, "que es permitido que cualquier controversia

8. Jum Manuel Trayter, "El arbiraje de Derveho Administnativo", en Revista de Admisistración Püblica,

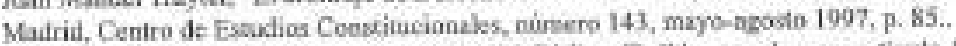

9. En la codificación vigenic, ef articulo 1505 del Codtigo Civil ha pasada a ser articulo 1478. 
susceptible de transacción, por el consentimiento de las partes, pueda ser llevada a arbitraje y mediación ${ }^{\prime \prime 10}$.

Antes de promulgarse la Ley de Arbitraje y Mediación comenzaron a desarrollarse ciertos planteamientos favorables al arbitraje, que se oponian a los puntos de vista a los que se ha hecho referencia y trataban de encontrar espacios para la utilización de métodos alternativos de solución de conflictos entre la administración y los particulares.

Estos planteamientos se hicieron a partir de la distinción que se estableció entre las controversias derivadas del ejercicio de potestades públicas (que se seguía considerando como no arbitrables), y aquéllas que tenían su origen en desacuerdos sobre interpretaciones de aspectos técnicos de los contratos.

La distinción creó un espacio adecuado para introducir el arbitraje en la actividad administrativa, pues extraía determinados temas del ámbito de las potestades públicas. En otras palabras, se pensaba que si bien el ejercicio de los poderes públicos no debía someterse a arbitraje, habia aspectos de la actividad administrativa que no tenian que ver con ellos y que se relacionaban, más bien, con criterios de orden técnico.

Si, por ejemplo, en un contrato de obra se estipulaba la necesidad de que un rubro determinado se ejecutara a partir de ciertas especificaciones, el hecho de que las mismas se hubieran cumplido o no podía establecerse, no a partir del ejercicio de potestades públicas, sino por medio de constataciones propias de la técnica de la construcción. Que un árbitro estableciera si las especificaciones técricas se habian cumplido o no era, entonces, un problema eminentemente técnico, que partía de constataciones empíricas que podian hacer los profesionales en la materia, y no del ejercicio de potestades públicas. 
Esta posibilidad se admitió en el caso de los contratos de consultoria ${ }^{11}$. Al promulgarse la Ley de Consultoría ${ }^{12}$, se dispuso en el segundo inciso de su artículo 40 que "en todo contrato de consultoría se establecerá el procedimiento de arbitraje para la solución de las controversias de carácter técnico derivadas de su elaboración".

El mismo criterio se utilizó poco tiempo después para el caso de los contratos de ejecución de obras, prestación de servicios y adquisición de bienes celebrados por la empresa estatal petrolera PETROECUADOR, al promulgarse el Reglamento de Contratación de la misma para obras, bienes y servicios específicos ${ }^{13}$. El artículo 5 de ese Reglamento disponia que "Petróleos del Ecuador y sus filiales podrán celebrar convenios transaccionales para precaver o terminar litigios, o recurrir al procedimiento arbitral pata solucionar litigios de carácter técnico".

Es interesante destacar que en el dictamen del Procurador General del Estado, que se citó anteriormente, se sostiene que una norma como la transcrita, por el hecho de constar en un Reglamento, no era aplicable, pues la posibilidad del arbitraje solo podía establecerse por medio de una norma con rango de Ley' Se trata, sin duda, de una muestra clara de cómo la práctica administrativa ecuatoriana anterior a la promulgación de la Ley de Arbitraje y Mediación, incluso cuando se planteaba la clara diferencia entre las potestades públicas y las controversias de orden técnico, era completamente reacia a admitir que controversias como las originadas en contratos celebrados por el sector público, pudieran resolverse por medio del arbitraje.

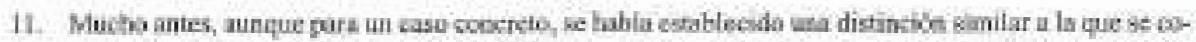
menta en el ieso. Fin el Decrdo Ley 580 (Registro Oficial ?16 de 22 de marzo do 1966), ea el que se establecierco las coudéciones del coenato de povisión del secvicha de enengia elḱctrica que celebraron

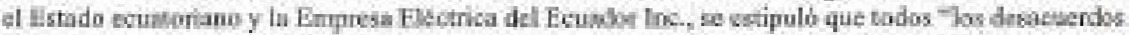
de nahuraleza contable, o los que surgieres resjecio a cualquier invpuario y avalúe realisados de con-

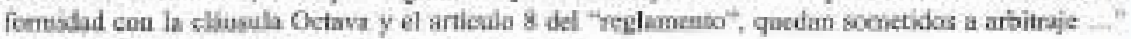
(cLisusula novera),

12. Regisso oficial 136 ov 24 de febrero de 1989

13. Decreto Ejecutivo 934 , suplemsenie del Registro O6sial 283 de 26 de expriembre de 1989

14. Ofieio 7515 de 16 de sepliembre de 1999 . 
La distinción entre controversias juridicas relacionadas con el ejercicio de las potestades públicas, y controversias técnicas en las que no se discutía ese ejercicio, permitió dar un paso hacia la arbitrabilidad de controversias derivadas de contratos celebrados por las instituciones del Estado. Se trata, por otra parte, de una distinción establecida en otros ordenamientos jurídicos, como el venezolano; Allan Brewer-Carias, al referirse a este tema, cita un criterio de la Procuraduría General de la República de Venezuela y concluye que, según ésta, "es necesario, al hablar del recurso al arbitramento, distinguir claramente qué cuestiones pueden someterse válidamente al mismo. Respecto a las cuestiones técnicas, las discrepancias que puedan presentarse entre las partes pueden ser resueltas por tribunales arbitrales. Sin embargo, en criterio de la Procuraduría, respecto a las cuestiones sobre interpretación y cjecución del contrato, éstas no pueden ser sometidas válidamente a arbitramento"15.

Otro paso para introducir el arbitraje en el Derecho Administrativo se dio al promulgarse la Ley de Modernización del Estado, Privatizaciones y Prestación de Servicios Públicos por parte de la Iniciativa Privada ${ }^{16}$. El artículo 63 de esta última disponia que las controversias suscitadas en relación con procesos contemplados en ella, podian resolverse por medio de arbitraje nacional 0 internacional, en "los asuntos que versaren sobre materia comercial $^{\prime \prime}$.

La referencia a temas de indole comercial hace una distinción similar a la de la Ley de Consultoría, aunque en un campo distinto; se trata, en todo caso, de una nueva muestra del recelo entonces existente para aplicar la institución arbitral en el ámbito del Derecho Administrativo.

Un poco antes, y sin distinciones de ningún tipo, la reforma que se introdujo en 1993 al artículo 10 de la Ley de Hidrocarburos, estableció la posibilidad de que las controversias derivadas de

15. Allm Hrener-Cariss, Contrans Administrativas, Caracas, Editorial Jurldica Vencrolans, 1992, pp. 263.264.

16. Registro Oficial 349,31 de dieiemhre de 1993. 
contratos regulados por ese cuerpo legal se sometieran al "procedimiento de arbitraje reconocido por la Ley ectuatoriana, de acuerdo a lo establecido en los contratos ${ }^{1217}$.

La amplitud de la norma, sin embargo, no eliminó el recelo de la administración hacia el arbitraje ni impidió que a este último se lo siga considerando como algo extraño.

En efecto, en la práctica, la distinción entre lo arbitrable (los aspectos técnicos, por ejemplo) y lo no arbitrable (el ejercicio de potestades administrativas), siguió existiendo. Un buen ejemplo es el contrato de participación celebrado entre el Estado ecuatoriano y las compañias Oryx Ecuador Energy Company, Santa Fe Minerales del Ecuador, Sociedad Internacional Petrolera y Compañía Latinoamericana Petrolera, el 20 de marzo de 1995, para la exploración y explotación de petróleo en el bloque 21 de la Región Amazónica.

La cläusula vigésima del referido contrato estipulaba con claridad que "los desacuerdos sobre asuntos de carácter técnico que involucren aspectos de carăcter económico y viceversa", se someterían a arbitraje; en otras palabras, se dejaba expresa constancia de que el arbitraje se limitaba a temas que estaban fuera del ejercicio de potestades administrativas o que implicaran la necesidad de que los árbitros juzguen la validez de actos administrativos.

El reconocimiento del arbitraje como una via válida para la solución de controversias, y su utilización generalizada por el sector público, se dio a partir de la promulgación de la Ley de Arbitraje y Mediación ${ }^{18}$; solo desde entonces, como sostiene la Procuraduria General del Estado, "es permitido que cualquier controversia susceptible de transacción, por el consentimiento de las partes, pueda ser llevada a arbitraje y mediación"19.

17. Ley 44, Registro Oficial 326,29 de noviembre de 1993

18. Rectatro Ofieial 145, 4 de septiembre de 1997. El testa codificado de la Ley se publicó en el Registro Officinl 417 , del 14 de diciombre de 2005 .

19. Oficio 7513 de $16 \mathrm{de}$ septiembre de 1999 
En todo caso, conviene anotar que el auge del arbitraje durante la primera década del siglo XXI se debio, más que a la ley misma, a la actuación de un Procurador General decididamente partidario de esta forma de solución de controversias, que impulsó la inclusión de cláusulas de arbitraje en los contratos administrativos sobre los que le tocó informar.

En el sector público, me parece, el recelo no ha sido superado y se fundamenta en una serie de supuestas verdades, sin ningún sustento en estudios de casos concretos, pero que muchos aceptan sin beneficio de inventario: "Ios árbitros favorecen al sector privado"; el sector público siempre pierde los arbitrajes"; "los árbitros son empleados de los contratistas", etc.

Hay quienes sostienen que el arbitraje para el sector público se ha establecido definitivamente en el Ecuador e, incluso, ha obtenido rango constitucional gracias al reconocimiento que hace el segundo inciso del artículo 190 de la Carta Fundamental.

Creo, sin embargo, que ese es un modo de ver las cosas que no va más allá de lo superficial. El reconocimiento constitucional, lejos de apuntar a un desarrollo del arbitraje, lo que pretende es limitar la alternativa al introducir un escollo fundamental: la autorización de la Procuraduría General, a la que se hará referencia más adelante.

En realidad, los recelos ocultos que nunca se disiparon han renacido y son los que hoy definen el tratamiento que debe darse al arbitraje; no hay mejor ejemplo de ello que el oficio T.1-C.1SNJ-12-1134, de 5 de octubre de 2012, mediante el cual el Secretario Nacional Jurídico de la Presidencia de la República transmite a las autoridades de las administraciones públicas central e institucional, la disposición del Presidente de la República en el sentido de que "los diversos contratos que se suscriban a partir de esta fecha, deberán someterse a la jurisdicción de los Tribunales Ordinarios y no a la de los Tribunales Arbitrales". 


\section{Arbitraje EN DERECHO}

El arbitraje, dice el artículo 3 de la Ley de Arbitraje y Mediación, puede ser en equidad o en derecho, y no establece ninguna regla especial para el caso de la administración pública. Tampoco lo hacía la Ley Orgánica de la Procuraduría General del Estado promulgada en $1998^{20}$, cuyo artículo 18 se remitia, en el inciso final, a las normas de la Ley de Arbitraje y Mediación. ${ }^{21}$

Desde un inicio, sin embargo, fue claro que la administración pública, sometida al principio de legalidad, no podía estar sujeta a un arbitraje en equidad. De hecho, en general las instituciones del sector público tuvieron la precaución, al momento de pactar arbitraje, de indicar claramente que el mismo sería en derecho.

Pronto el tema alcanzó consagración legislativa al promulgarse una nueva Ley Orgánica de la Procuraduría General del Estado, en $2001^{22}$. El artículo 11 de esa Ley disponía:

Los organismos y entidades del sector público podrán someterse a procedintientos de arbiltaje de derecho y a la mediación nacional o infernacional, de acuerdo a lo establecido en la Ley de Arbitraje y Mediación, o en instrumentos internacionales que los faculte, previa la suscripcion del respectivo convenio.

Surgida la controversia, los organismos y enfidades del sector páblico pueden someterse a arbilmie de derecho o mediación, de conformidad con las leyes pertinentes. Para someterse al arbitraje internacional requerinán además la autorización de la Procuruduría General del Estado.23

El mandato de la Ley Orgánica de la Procuraduría General del Estado ha alcanzado rango constitucional a partir de octubre de 2008: en el caso de la contratación pública, dice el artículo 190 de la Constitución, procede el arbitraje en derecho.

20. Registro Oticial 335, 9 de jumio de 1998.

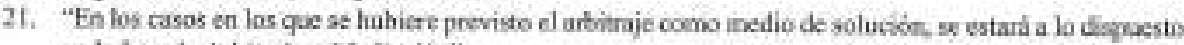
en la Ley de Artitraje y Mediación".

22. Registre Oficial 372, 19 de julio de 200t. En le ley vigene (Registro Oficial 312,17 de abril de 2004) se manticne el mimo texto, tumbien como sticulo 11.

23. Los subrayados son mies. 
Pese a la claridad de estos mandatos, hay quienes sostienen que pueden presentarse problemas si las partes contratantes no especifican la naturaleza del arbitraje o si pactan un arbitraje en equidad.

En el primer caso, el problema se presentaría por la existencia del artículo 3 de la Ley de Arbitraje y Mediación, según el cual, a falta de estipulación de las partes, debe entenderse que el arbitraje será en equidad ${ }^{24}$.

Para los contratos celebrados con posterioridad a la Ley Orgánica de la Procuraduría General del Estado de 2001, es claro que en la medida en que se incorporan a ellos las normas vigentes al momento de su celebración, tanto el artículo 11 de la referida Ley como, a partir de 2008, el 190 de la Constitución, deben entenderse como parte de los contratos y, en consecuencia, las controversias que de ellos se deriven y se sometan a la jurisdicción arbitral, deben ser resueltas siempre en derecho.

¿Pero qué ocurre con los contratos celebrados antes de la vigencia de las normas indicadas? ¿Se les aplica el artículo 3 ya citado $y$, en consecuencia, a falta de pacto expreso debe entenderse que el arbitraje es en equidad?

Esta sería, me parece, una forma privatista de abordar un problema propio del Derecho Administrativo.

En este último debemos partir de un principio fundamental, recogido tanto por la Constitución vigente como por la que la precedió 25 : el principio de legalidad. En virtud de este principio, las instituciones y servidores públicos no tienen más atribuciones que aquéllas que les confiere la ley y es esta última la que define la forma en que deben ejercerse las competencias.

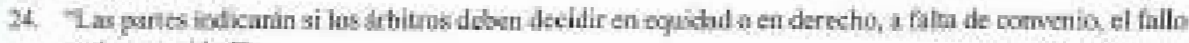
será en equidiad"

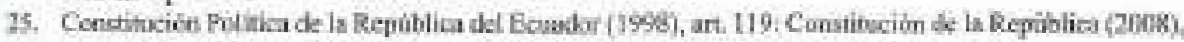
art. 226. Los dos tersas, si bien fienen pecuenas diferencias de robeciben, sees iguales. 
Si esto es asi, no cabe que a quienes la Constitución impone el deber de actuar en virtud de la legalidad, se las pueda juzgar con criterios de equidad.

La aplicación del principio constitucional y de la Ley Orgánica de la Procuraduría General del Estado, en consectrencia, exige que en todos los casos, aún en aquellos en que exista silencio de las partes, el arbitraje derivado de contratos celebrados por instituciones del Estado sea un arbitraje en derecho.

En el caso de cláusulas que pacten arbitraje en equidad, parece claro que la voluntad de las partes no puede modificar un claro mandato constitucional y legal y, en consecuencia, la jerarquía superior de la Constitución y de una Ley Orgánica, deben prevalecer sobre una mera estipulación contractual.

Conviene hacer notar, en este punto, lo que muy bien aclaró en su momento Édgar Neira:

... el requisito de que la controversia arbitral con parte estatal se resueloa en derecho, no es condición de validez del comvenio arbitral. Se trata de una exigencia relativa al alcance del pronunciamiento de los árbitros en el laudo que expidan para poner fin al litigio arbitral. 20

En consecuencia, si las partes no definen si el arbitraje es en derecho, o si pactan un arbitraje en equidad, tanto la Constitución como la ley suplen en el un caso, y corrigen en otro, lo hecho por los contratantes, sin que ninguno de los dos casos pueda considerarse que ha sido afectada la validez del pacto arbitral. Libro Anual de in Asincisción Escueba de Dereche de ia Pontificia Universidad Católica del Ecoador. No. $51,2007,5,58$. 


\section{LA PUBLICIDAD DEL ARBITRAJE}

La confidencialidad del arbitraje es una posibilidad que depende del convenio de las partes, conforme el artículo 34 de la Ley de Arbitraje y Mediación²; i esto, unido a las reglas de confidencialidad de los centros de arbitraje, convierte en la práctica a los procedimientos arbitrales en reservados, e impide que puedan ser conocidos por quienes no hayan participado como parte en los mismos.

La confidencialidad es plenamente explicable en el ámbito del derecho privado, pues a nadie se le puede exigir que publique los detalles de las controversias que mantiene con otras personas.

En el derecho público ocurre exactamente lo contrario: la publicidad es la regla de toda actuación administrativa y solo se consideran reservados los temas a los que una ley califica expresamente como tales. "No existirá reserva de información", dice el número 2 del artículo 18 de la Constitución, "excepto en los casos expresamente establecidos en la ley".

Debe tomarse en cuenta que en la Ley de Arbitraje y Mediación no hay un mandato de confidencialidad, sino únicamente una norma que autoriza a las partes a guardar reserva sobre el contenido de un arbitraje.

Esta posibilidad de pactar reserva es, obviamente, aplicable tan solo a los privados; la administración pública no puede pactar mantener en reserva una información determinada y, si lo hace, viola la Constitución y, en consecuencia, el pacto carece de valor.

La generalizada idea de que los procedimientos arbitrales deben ser confidenciales también cuando interviene la administración carece, por lo tanto, de todo sustento.

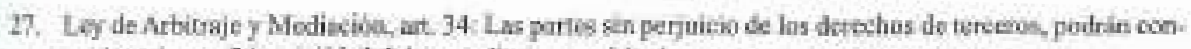
venir en la coefidencialidad divl procedimiento arbitral .. 
La consecuencia de lo dicho es que ningún Centro de Arbitraje podría negarse a conceder a quien los solicite copias de los procedimientos arbitrales en los que sea parte la administración pública, y que los laudos que sean consecuencia de los mismos pueden publicarse sin ninguna restricción.

\section{La autorización del Procurador General del Estado}

Conforme los artículos 4 de la Ley de Arbitraje y Mediación y 11 de la Ley Orgánica de la Procuraduría General del Estado, hay dos vías para que una institución del Estado se someta a arbitraje: por medio de una estipulación contractual antes de que surja la controversia o, una vez que esta última se ha presentado, con la celebración de un convenio. En este último caso, sin embargo, la ley exige que se cuente con la aprobación del Procurador General del Estado.

La nueva Constitución, vigente desde octubre de 2008, introduce una novedad en este campo, cuando al reconocer el arbitraje como una vía posible para solucionar controversias de las que sea parte el sector público, se refiere a la autorización del Procurador General del Estado. Dice el segundo inciso del artículo 190 de la Constitución:

En la contratación pública procederá el arbitraje en derecino, previo pronuenciamiento favorable de la Procuraduría General del Estado, conforme a las condiciones establecidas en la ley.

Siempre consideré que el sentido de la norma transcrita era completamente claro, e implicaba introducir un requisito adicional, en todos los casos, para que las instituciones del sector público puedan someterse a un arbitraje: la autorización previa de la Procuraduría General del Estado. 
Se ha generado, sin embargo, un debate sobre el verdadero alcance del mandato constitucional, pues un importante grupo de árbitros sostiene que, en realidad, la autorización de la Procuraduría General sería necesaria solo en algunos casos. Para este sector de juristas, la frase final del segundo inciso del artículo 190 ("conforme a las condiciones establecidas en la ley"), se refiere al pronunciamiento de la Procuraduría y, en consecuencia, debe entenderse que ese pronunciamiento es exigible solo cuando una ley lo establece.

Tanto para sostener esta tesis, como para contradecirla, se han expuesto argumentos doctrinarios y se han revisado las actas de la Asamblea Constituyente. El problema, sin embargo, me parece más simple y se reduce a un asunto de orden gramatical.

Cuando se sostiene que la frase "conforme a las condiciones establecidas en la ley", se refiere al pronunciamiento favorable de la Procuraduría General del Estado, no se toma en cuenta que entre la referencia al Procurador y la frase final de la norma que nos ocupa, hay una coma, y esa coma establece una diferencia fundamental en el texto.

En efecto, para que podamos entender que las condiciones establecidas en la ley se relacionan al pronunciamiento de la Procuraduría, el texto debería decir: "previo pronunciamiento favorable de la Procuraduría General del Estado conforme a las condiciones establecidas en la ley", sin coma entre las palabras "Estado" y "conforme".

Pero la coma entre esas palabras existe y hace que el texto deba entenderse de una manera distinta, pues lo que tenemos es un párrafo en el que la frase "previo pronunciamiento favorable de la Procuraduría General del Estado", consta entre comas y, en consecuencia, no se refiere a la última parte del texto, sino a la primera. 
Esto porque la frase indicada es lo que gramaticalmente se considera un inciso, esto es, un elemento complementario que aporta precisiones, ampliaciones, rectificaciones o circunstancias a lo dicho ${ }^{28}$, y lo dicho es lo que precede al texto. Los incisos funcionan como estructuras explicativas "que interumpen el curso del enunciado, "para agregar alguna precisión o comentario sobre el elemento nominal que las precede $\mathrm{e}^{n 29}$.

La frase entre comas, entonces, está ahí para explicar un texto anterior; en nuestro caso, la referencia al pronunciamiento de la Procuraduría General del Estado explica la frase que admite la posibilidad del arbitraje en derecho.

Una estructura explicativa puede omitirse sin que el texto cambie de sentido; lo único que ocurre es que se pierde la precisión. En la norma que analizamos, si eliminamos el entrecomillado, la disposición diría lo siguiente: "En la contratación pública procederá el arbitraje en derecho conforme a las condiciones establecidas en la ley".

Lo que agrega el entrecomillado es la explicación de que ese arbitraje en derecho que procede conforme a las condiciones que establece la ley, requiere el pronunciamiento previo de la Procuraduría General.

Esto se entiende mejor si hacemos algo plenamente posible cuando se trata de estructuras explicativas: en lugar de colocarla en la mitad del texto, la trasladamos al final ${ }^{30}$; en ese caso, la norma diria: "En la contratación pública procederá el arbitraje en derecho conforme a las condiciones establecidas en la ley, previo pronunciamiento favorable de la Procuraduría General del Estado".

28. Real Acadesaiz Esprñola, Crtografla de le Lengua Espanola, Madrid, Espaca, 2012, D. 307.

29. Ilsed, p. 308 .

30. "... aunque los incises prosotipicos sun secuencias que intanumpen el enunciado y apurcoen en posieibn

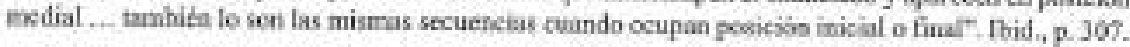


Parece claro que, si enfocamos el tema desde el punto de vista gramatical, el texto que se comenta tiene un único sentido, pues la frase entrecomillada sirve para explicar a la frase precedente, y no forma parte de la que le sigue. La segunda coma del texto, entonces, es fundamental, pues su presencia da a la norma un sentido completamente distinto al que pretenden quienes en su lectura pasan por alto la presencia del signo de puntuación.

Si el sentido del mandato constitucional es, conforme se ha visto, establecer un requisito adicional para que las entidades del sector público puedan pactar arbitraje, cabe preguntarse cuál es la consecuencia de que una institución del Estado acepte utilizar la via arbitral para la solución de una controversia, sin contar con el pronunciamiento de la Procuraduría General del Estado.

Para que proceda el arbitraje en derecho, dice el artículo 190 de la Constitución, se requiere el pronunciamiento previo de la Procuraduría General del Estado; es claro, entonces, que sin ese pronunciamiento, el arbitraje no procede; en otras palabras, un pacto arbitral que prescinda del requisito constitucional, sería nulo.

La omisión de los requisitos o formalidades que las leyes prescriben para el valor de ciertos actos o contratos, dice el artículo 1698 del Código Civil, produce nulidad absoluta. Es el caso de los contratos sometidos a la Ley del Sistema Nacional de Contratación Pública, el número 2 del artículo 65 de esta última establece, como causa de nulidad de los contratos, el haber prescindido de los procedimientos legalmente establecidos.

En consecuencia, si la Constitución establece un requisito previo para el pacto arbitral, el incumplimiento de ese requisito es causa de nulidad del pacto, pues no es admisible que se considere válidas actuaciones que no se han sometido a los procedimientos establecidos en el ordenamiento juridico, con mayor razón si se trata de la administración pública, sometida al principio de legalidad. 
No debe olvidarse, finalmente, que conforme el artículo 1699 del Código Civil, la nulidad absoluta se declara de oficio, "cuando aparece de manifiesto en el acto o contrato". 